THE VALUE OF HUMAN LIFE: A REVIEW OF THE MODELS

Joanne Linnerooth

RR-80-25

June 1980

Reprinted from Economic Inquiry, volume 17 (1979)

INTERNATIONAL INSTITUTE FOR APPLIED SYSTEMS ANALYSIS Laxenburg, Austria 
Research Reports, which record research conducted at IIASA, are independently reviewed before publication. However, the views and opinions they express are not necessarily those of the Institute or the National Member Organizations that support it.

Reprinted with permission from Economic Inquiry 17: 52-74, 1979.

Copyright $\odot 1979$ Western Economic Association.

All rights reserved. No part of this publication may be reproduced or transmitted in any form or by any means, electronic or mechanical, including photocopy, recording, or any information storage or retrieval system, without permission in writing from the copyright holder. 


\section{FOREWORD}

IIASA's concern for the management and decision problems associated with highrisk situations has a number of roots. One was a joint project on risks associated with nuclear energy involving IIASA's Energy Program and the International Atomic Energy Agency. Another examined the institutional aspects of two oilwell blowouts in the North Sea. From these interests has grown a study of the management problems of hazard and risk in a variety of different situations.

This report, which was developed from work done by Joanne Linnerooth as part of the joint IAEA/IIASA project, considers the value of human life, an issue as important for current work at IIASA as studies that have been done in the past. Thus, it deals with a necessary element in a comprehensive approach involving technology, economics, decision analysis, and social science to the full range of managerial and institutional problems associated with establishing and operating hazardous industrial activities.

ROLFE TOMLINSON

Chairman

Management and Technology Area 


\title{
THE VALUE OF HUMAN LIFE: A REVIEW OF THE MODELS
}

\author{
JOANNE LINNEROOTH *
}

This paper reviews four consumer maximization models where the probability of premature death enters as a variable that is both known to the consumer and under his control. These models generate a number of interesting results with respect to a person's willingness to pay for an increased chance of living. The most useful to the cost-benefit analyst is the derived relationship between this willingness-to-pay value and a person's lifetime earnings, and thus the relationship between the theoretically correct willingness-to-pay approach to the valuation of life-saving programs and the widely-used humancapital approach. However, the conclusions of the reviewed models are in this regard conflicting. Two of the models establish a theoretical basis for investigating the correlation of these two measures; however, this basis is shown to follow from an unrealistic assumption concerning the person's lifetime utility function. The remaining two models, although based upon more realistic assumptions, do not claim to provide theoretical grounds for making such investigations. The conclusion of this review is that in the absence of available data on personal demand for increased survival probability it is impossible to determine the relationship between the willingness-to-pay and the human-capital approaches to placing a value on human life.

One of the most difficult problems facing the cost-benefit analyst is the evaluation of public policies or investments which could result in the loss or saving of human life. A widely accepted procedure for "pricing" an expected change in population mortality is to estimate the expected loss in earned income; here the value of a person's life is calculated as his discounted expected future earnings. This human-capital approach 1

\footnotetext{
*International Institute for Applied Systems Analysis; Joint International Atomic Energy Agency/International Institute for Applied Systems Analysis Research Project, Vienna, Austria. I wish to acknowledge the valuable advice and criticism received from Jack Hirshleifer, who devoted considerable time to earlier drafts of this paper. Martin Bailey, Lester Lave, M. Jones-Lee, Martin McGuire and Dan Usher also provided many helpful comments. The responsibility for any remaining errors is solely mine.

1. The human-capital approach has a long history: Its original intent was to estimate optimal life insurance (e.g., Woods and Metzger, 1927; Dublin and Lotka, 1940); later it served as a measure of the economical losses from accident or disease (e.g., Fisher, 1909; Reynolds, 1956; Weisbrod, 1965); and more recently it has been adopted as a measure of benefits from life-saving programs (e.g., Fromm, 1965; Lave and Seskin, 1970; Otway et al., 1971; White House Office of Science and Technology, 1972; National Highway Traffic Safety Administration, 1972). For the last purpose, other suggested methods have been derived from jury awards (Thedie and Abraham, 1961) and
}

Economic Inquiry

Vol. XVII, Jan. 1979 
remains popular despite the criticism that it takes account only of society's loss in national income and ignores the person's own desire to live. ${ }^{2}$

From the point of view of economic welfare criteria ${ }^{3}$ a more appropriate measure of the benefits arising from a decrease in population mortality ${ }^{4}$ would include the consumer's interest - the desire of each person at risk to avoid premature death. But as the number of deaths averted by public expenditures is usually known only statistically, that is, there are no named individuals who would almost certainly die in the absence of the expenditure, the relevant measure need not take into account a person's preference for avoiding death, but rather his preference for avoiding some small probability of death. For this reason Mishan (1971) suggests that if alternative allocations are to be compared by their potential for a Pareto improvement, then these preferences should be expressed in terms of the willingness of each person to pay for the (usually) marginal reduction in mortality risk. ${ }^{5}$

The question arises whether the value of a person's life implied by his willingness to pay to reduce a small chance of death differs greatly from the value calculated by the widely-used human-capital measure. Schelling (1968), who was the first to address this question, suggests that there are no grounds for assuming that the two measures are the same: "...there is no reason to suppose that a man's future earnings, discounted in any pertinent fashion, bear any particular relation to what he would pay to reduce some likelihood of his own death" (p. 149).

The empirical evidence on this question is not conclusive. There have been several attempts to infer the price of risk-taking from the relationship between risky jobs and their respective wage rates; ${ }^{6}$ however, there are several limitations to this market approach, the most critical being the implied assumption that the workers perceive the risks accurately and have the necessary mobility to change their occupation. A second

from insurance decisions on life saving (Morlat, 1970; Starr, 1969). More recent discussions of the life-valuation problem from a decision-theoretic point of view can be found in Zeckhauser (1975) and Raiffa et al. (1976). For a survey of this literature, see Linnerooth (1975, 1976).

2. For original critiques of this approach, see Thedie and Abraham (1961), Roesch (1961), Schelling (1968), and Mishan (1971).

3. Here we are referring to the Kaldor-Hicks criterion of welfare change.

4. In this paper I will refer generally to the benefits of decreased mortality, or life saving; the costs of life risking can be considered symmetrical.

5. Mishan argues that familial and social interest in reducing a person's chances of death is also an important, and probably unmeasurable, factor. Yet there is some economic justification for this exclusion if we assume that this interest is internalized in the individual's demand for increased life expectancy, an assumption implicit in most welfare economics. In any case, the individual's interest in his own protection is probably the dominant factor.

6. For example, Thaler and Rosen (1973) found that in their sample the workers value their lives at around $\$ 200,000$. This figure has been revised and up-dated by Bailey (1976). See also Smith (1973) and Rappaport (1974). 
possibility for estimating willingness to pay is simply to ask people what it is worth to them to increase their survival chances. ${ }^{7}$ But survey approaches have also been criticized on the grounds that people have difficulty in assessing probabilities and answering hypothetical questions. ${ }^{8}$

A final approach is to generate a person's willingness to pay for an improved chance of living by placing a priori restrictions on the form of his lifetime utility function. This is the approach taken by Usher (1971), Jones-Lee (1974), Cook and Graham (1975) and Conley (1976). The Usher and Conley models offer the most restrictive formulations of the lifetime utility function, which, contrary to Schelling's conjecture, result in a specific relationship between a person's lifetime earning and his willingness to pay to reduce some probability of his own death. This relationship provides a basis for deriving quantitative information on willingness to pay. Alternatively, the models of Jones-Lee and of Cook and Graham, which are based upon less restrictive forms of the lifetime utility function, do not result in a formal relationship between the humancapital and willingness-to-pay approaches to life valuation. From their state preference approach, the authors develop interesting results concerning the value of current-period changes in the risk of death; their analyses, however, do not provide a basis for deriving quantitative information on this value. Since the analyst's interest in these models stems mainly from their potential to generate a measure of willingness to pay, it is important to assess the merits of the Usher and Conley approach versus those of Jones-Lee and of Cook and Graham.

The purpose of this review is to compare and contrast the formulations of these four models, paying particular attention to the plausibility of the underlying assumptions. The first section presents a simple model of expected utility maximization for the purpose of defining the "value of human life" within the context of consumer choice theory. This model, where lifetime utility is a function of lifetime consumption, provides the background for the discussion of the Usher and Conley models, which follows in the second section. The interpretation of Conley's formulation by Hirshleifer, et al. (1974), and especially in Appendix 2 by Rappaport, clearly shows the implied relationship between the willingness-to-pay and the human-capital approaches, and thus forms the basis of the discussion in the third section. The next section presents a broader interpretation of lifetime utility which illustrates the sensitivity of Usher's and Conley's results to their assumed form of the objective function. Finally, a discussion of the Jones-Lee model and the Cook and Graham model, where lifetime utility is conditional upon the states "life" and

7. Responses to one questionnaire (Acton, 1973) designed to determine the demand for emergency coronary care units indicated that large groups would be willing to pay from $\$ 28,000$ to $\$ 43,000$ for each expected life saved in the community.

8. See Fromm (1968). 
"death," is presented, and their results are contrasted with those of the Usher and Conley models.

\section{A SIMPLE MODEL}

It is important to clarify what is meant in this paper by the provocative term, "value of human life." Since the analyst is concerned not with the rescue of named individuals (or, for that matter, with the sentencing of named persons to certain death) but with marginal changes in individual risk levels, a more appropriate term would be "value of risk reduction." Yet any allocative decision that affects individual risk levels does implicitly place a priority or a value on human life, and a major purpose of the cost-benefit calculus is to make these values explicit. ${ }^{9}$ In other words, for a small probability of loss of life there is a conceptual value of life which, when multiplied by this probability, yields the maximum a person would be willing to pay for the stated improvement in his survival chances.

This concept can be illustrated in the usual manner by the tradeoff between wealth and survival probability or by the slope of the indifference function in Figure 1. The convexity of this function assures a nonunique value of life since the payment for a marginal increase in $P$ depends on the level of $P$. If, for example, the average person is willing to pay $\$ 200$ for a reduction in mortality risk from $10^{-6}$ to $10^{-9}$, this does not mean that he is willing to pay $\$ 200$ to reduce a mortality risk by $10^{-3}$ when the risk is originally $10^{-7}$, nor that he is willing to pay $\$ 200,000$ to eliminate certain, immediate death. The $\$ 200,000$ figure is a measure of the value of life only in the sense that the analyst can justifiably use it as a measure of the benefit from a policy that results in a per-capita mortality risk reduction from $10^{-6}$ to $10^{-9}$ over a population numbering 1,000 ; here the expectation is the saving of one life.

Although the nonlinearity of the indifference function illustrated in Figure 1 is intuitive, its shape can be verified with a simple model of consumer choice, where the consumer has knowledge of and control over his survival chances. The problem is to structure an individual's preferences over survival and wealth. As explained above, we can think of survival as a probabilistic term for an increase in life expectancy; the demand for survival would then be willingness to pay for this increase.

If we consider an individual who commences the current period with full information on his expected lifetime, his probability of surviving any given period, i.e., his age-specific survival rate, can be denoted as $p_{t}$, and his probability of being alive at the end of any given period, as $P_{t}$. We

9. Fried (1969) was the first to point out the apparent anomaly that society is prepared to expend far greater resources to save the lives of known persons in present peril than to save a statistical life. Raiffa (1976), arguing that these tradeoffs should be made much more explicit, calls this practice the "murdering of statistical lives." 
FIGURE 1

An Indifference Function Showing the Tradeoff of Wealth for Survival Probability

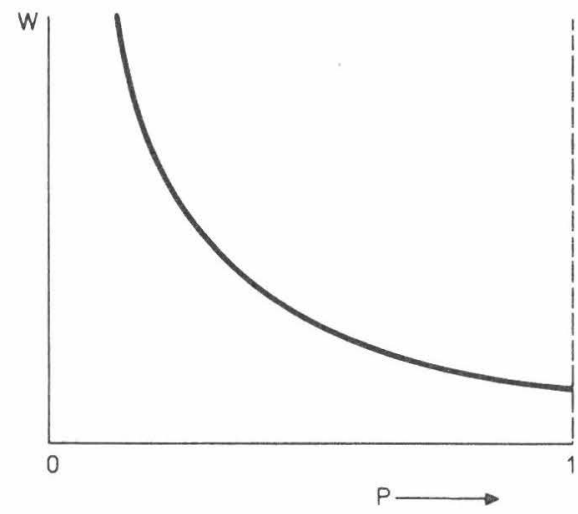

assume here that $p_{t}$ occurs on the first day of the period, and therefore $P_{t}=S_{t} p_{t}$, where $S_{t}$ is the probability of surviving until year $t$ or $S_{t}=$ $p_{t-1}, p_{t-2}, \ldots, p_{0}$. It follows that the demand for an increase in life expectancy can be expressed in terms of the demand for an increase in any age-specific survival rate, $p_{t}$. This demand could be expected to depend, among other things, upon the individual's current age or expected lifetime, his current wealth and income, the number of his dependents, and the nature and timing of the probabilistic death.

We can begin by considering the problem in its simplest form. For this purpose we assume that the individual is a "lone bachelor," i.e., he has no family or friends who have an interest in his survival. Thus the complications of interdependent utilities and any motive on the part of the individual to bequeath his wealth are eliminated. We assume further that the individual regards his lifetime as fixed if he survives the initial period. Whether or not he survives is determined on the first day when he faces some probability of dying, denoted $1-P_{0}\left(P_{0}=p_{0}\right)$. Because the resolution is instantaneous, he suffers no anxiety. In addition, we assume that the individual has a certain fixed wealth which he distributes throughout his lifetime. There are no opportunities for saving, investing or bequeathing, so this wealth can be regarded as lifetime consumption, denoted $C$. (We will use upper-case letters to refer to lifetime variables and lower-case letters to refer to variables relevant to shorter periods of time, typically one year).

We will also make the important assumption that the individual behaves as an expected utility maximizer. ${ }^{10}$ If a utility is assigned to each

10. Different sets of axioms which imply that the individual maximizes expected utility are presented in von Neumann and Morgenstern (1947); Savage (1954); and Luce and Raiffa (1957). 
year of his life, then he behaves so as to maximize his expected utility or his total utility weighted by the probability of his survival. In this way, expected years of life enter the individual's lifetime objective function indirectly as a weighting factor. He is assumed to make a quantity-quality tradeoff by buying increases in his survival probability until he has maximized his expected lifetime utility.

To be consistent with the formulations of Usher, and of Conley, we will express the objective function, or expected lifetime utility, as a function of lifetime consumption. Since the individual begins the initial period with a certain wealth (lifetime consumption), this objective function can be written

$$
E\left(U^{L}\right)=P_{0} U(C),
$$

where $E\left(U^{L}\right)$ represents expected lifetime utility, $P_{0}$ is the probability of surviving the current period, and $U(C)$ is the utility of lifetime consumption. The individual would then be indifferent; that is, he would maintain the same expected utility, given changes in consumption and survival probability which hold the expression in (1) constant. His implied marginal rate of substitution between $P_{0}$ and $C$ can be calculated by taking differentials of this expression, given $d E\left(U^{L}\right)=0$; the result is

$$
\partial C / \partial P_{0}=-(U(C)) /\left(P_{0} U^{\prime}(C)\right),
$$

where $U^{\prime}(C)$ represents marginal lifetime utility with respect to lifetime consumption. It follows from the assumed equivalence of lifetime wealth and lifetime consumption that (2) specifies the slope of the indifference function (see Figure 1), thus representing what has been defined here as the value of human life. However, note that considerations such as family responsibilities, opportunities for wages and savings, and insurance options would complicate the model considerably.

Although there is little pretense of reality, one important property of (2) can be expected to be independent of the restrictive assumptions. This is the nonlinear relationship between changes in willingness to pay for marginal increases in survival probability and the level of this probability. As a person's survival chances decrease, his willingness to pay increases at an increasing rate; the indifference function (see Figure 1) asymptotically approaches, but never intersects, the $\mathrm{W}$-axis. As Bergstrom (in Hirshleifer, et al. (1974)) has pointed out, this formulation resolves the paradox that an individual, although he probably places an infinite value on his own life, willingly accepts small probabilities of death for finite compensation. ${ }^{11}$ It also leads to the anomaly that the

11. There is an interesting difference here between the risking of lives and the saving of lives. It can be argued from (2) that it is impossible to compensate a person fully for accepting certain and immediate death; yet individuals facing a very high risk of certain death are constrained by their budget with respect to the amount they can pay to reduce this risk. 
cost-benefit analyst following the precept of revealed preferences would not recommend that funds be allocated across projects such that the expected number of lives saved is maximized. To the contrary, he will recommend allocation of relatively more per expected life saved to the marginal reduction of the higher-level risk. ${ }^{12}$

\section{THE MODELS OF USHER AND CONLEY}

The models of Usher and Conley can most easily be reviewed by showing how they compare with or differ from the above formulation. With this in mind, each model will be discussed in turn.

(i) Usher's Model

Usher is concerned with the life-valuation problem from the point of view of developing social indicators that reflect an expanded concept of national welfare from the usual income or GNP measures. The inclusion of one such welfare change, decreased population mortality rates, requires some method of valuing or pricing these changes. For this purpose, Usher develops a model of life-cycle planning and asks what role uncertain mortality plays: what it is worth to the individual in terms of foregone consumption to decrease his risk of dying in any given (present or future) period?

Expected lifetime utility in Usher's formulation is a function of all past consumption and can be written

$$
E\left(U^{L}\right)=\sum_{t=0}^{n} R_{t} U_{t}(C),
$$

where $R_{t}$ is the probability of living exactly $t$ years, $n$ is the maximum length of life, and $U_{t}(C)$ is a function of consumption in each year in which the individual is alive, or

$$
U_{t}(C)=U_{t}\left(c_{0}, c_{1}, \ldots, c_{t-1}\right) .
$$

Since

$$
R_{t}=\left(1-p_{t}\right) S_{t},
$$

where $\left(1-p_{t}\right)$ is the mortality rate in year $t$ and $S_{t}$ is the probability of surviving until year $t$, expected lifetime utility becomes

$$
E\left(U^{L}\right)=\sum_{t=0}^{n}\left(1-p_{t}\right) S_{t} U_{t}\left(c_{0}, c_{1}, \ldots, c_{t-1}\right) .
$$

12. This principle violates what Fried (1969) originally referred to as the economist's maximizing strategy, which states that the same value should be assigned to the expectation of saving (losing) a life regardless of the level of risk. A reconciliation of this maximizing strategy with the willingnessto-pay approach is attempted in Linnerooth (1977). 
For purposes of comparison we can assume that lifetime utility over $t$ years is an additive function of utility in each year, or

$$
U_{t}\left(c_{0}, c_{1}, \ldots, c_{t-1}\right)=u_{0}\left(c_{0}\right)+u_{1}\left(c_{1}\right)+\ldots+u_{t-1}\left(c_{t-1}\right),
$$

from which it follows that (6) can be rewritten as

$$
E\left(U^{L}\right)=\sum_{t=0}^{n} S_{t} p_{t} u_{t}\left(c_{t}\right),
$$

where $S_{t}={ }_{i=0}^{t-1} p_{i}$. From (8) it is possible to specify the marginal rate of substitution between consumption and survival probability for any given period of the person's life. For instance, if it is assumed that he purchases an increase in survival probability from present consumption, this tradeoff can be written

$$
\partial c_{0} / \partial p_{t}=\left[\sum_{j=t}^{\infty}\left(p_{j} / p_{t}\right)\left(u_{j}-u_{t}\right)\right] /\left[\sum_{j=1}^{\infty} p_{j}\left(\partial u_{j} / \partial c_{0}\right)\right] .
$$

Considering only initial-period survival probability to conform to our simple model, we can write the above as

$$
\partial c_{0} / \partial p_{0}=-\left[u_{0}\left(c_{0}\right)+\sum_{t=1}^{\infty} S_{t} p_{t} u_{t}\left(c_{t}\right)\right] /\left[p_{0} u_{0}^{\prime}\left(c_{0}\right)\right] .
$$

The numerator in (9) expresses a person's expected lifetime utility in event that he survives the hazard of the initial period; this can be compared to the numerator of (2) which expresses certain lifetime utility, again if he survives the initial hazard. The important point is that here the value of life is directly related to lifetime utility of (expected) lifetime consumption.

(ii) Conley's Model

Usher's analysis describes the shape of the indifference function, or the tradeoff between immediate consumption (wealth) and survival probability that would leave the individual in an equivalent position if the changes in these variables were imposed upon him. In contrast, Conley develops a deterministic model of individual maximization, where consumption and survival probability enter as behavioral variables. Assuming that the individual is fully informed, infinitely sensitive, and interacting in competitive markets with zero transaction costs, Conley expresses the objective function as

$$
E\left(U^{\boldsymbol{L}}\right)=\Sigma_{t} \lambda(t) u(\cdot) p(\cdot),
$$

where expected lifetime utility $E\left(U^{L}\right)$ is separable into discounted, singleperiod utilities, $u(\cdot)$ is a single-period function, $p(\cdot)$ is the probability of being alive, and $\lambda(t)$ is the utility discount function. 
Since the purpose here is to establish the relationship between consumption and $p(\cdot)$, we will note only that both $u(\cdot)$ and $p(\cdot)$ are functions of all lifetime activities, including consumption. Thus, the single-period utility function becomes

$$
u(\cdot)=u\left(x^{1 t}, x^{2 t}, \ldots, x^{n t}\right)=u\left(X^{t}\right)
$$

for $n$ activities, denoted $x$, in period $t$, and where $X^{t}$ is the vector of activities. Conley defines consumption as an activity for which the individual must expend cash outlays, and production as an activity which results in cash income. When there is no activity, i.e., $x^{i t}=0$ for all $i$ 's, the individual is no longer alive. The utility of the state "death" can be arbitrarily set at zero, or

$$
u(0,0, \ldots, 0)=0,
$$

and $u(\cdot)$ is therefore determinable up to a multiple constant. In addition, Conley expresses $p(\cdot)$ as a function of $X^{*}$ (along with several other important variables such as age, outside influences, etc.), from which it follows that the objective function can be rewritten as

$$
E\left(U^{x}\right)=\Sigma_{t} \lambda(t) u\left(X^{t}\right) p\left(X^{t}\right)
$$

The individual maximizes expected utility subject to a monetary constraint requiring that expected lifetime consumption equals expected lifetime income plus wealth, or

$$
\Sigma_{t}^{\infty}(1 / 1+r)^{t-T} \Sigma_{t}\left\{\$^{i t} x^{i t} p\left(x^{i t}, \ldots\right)\right\}-W=0,
$$

where $r$ is the market rate of discount, $\$^{i t}$ is the monetary value associated with each unit of $x^{i t}$ such that $\$^{i t}>0$ when $x^{i t}$ is a consumption activity and $\$^{i t}<0$ when $x^{i t}$ is a production activity, and $W$ is wealth. According to Conley this constraint is feasible since, given the assumption of fullinformation and costless markets, a person could contract with an insurance company to turn over all his wealth and future income for the receipt of an allowance for consumption expenditures.

The equilibrium conditions for maximization of (13) subject to (14) are such that the marginal utility of activity $i$ must equal the expected loss of lifetime utility plus the marginal utility of both the monetary cost and the change in expected net labor income. From this equilibrium condition Conley derives the value of human life, $V$ (which he defines as the individual's own interest in his safety decision) as discounted expected lifetime consumption divided by the elasticity of discounted lifetime utility with respect to lifetime consumption. This can be written 


$$
V=-U^{L} /\left(p\left(\partial U^{L} / \partial C\right)\right) \stackrel{p \approx 1}{\equiv}-C /\left(\left(\partial U^{L} / \partial C\right)\left(C / U^{L}\right)\right) \equiv C / \alpha,
$$

where $\alpha$ represents the lifetime consumption elasticity of lifetime utility.

Conley defines the value of lifesaving that is appropriate for valuing the benefits of collective protection as $H=V+B$, where $B$ is equal to net labor income or the surplus of lifetime income over lifetime consumption. This concept, then, includes the economic losses accruing to others; however, in this full-information model the economic interests of others are internalized into the individual's decision-making process. For our purposes, it is important to note that the above expression is equivalent to the value of human life derived in (2).

\section{THE RESULTS}

An important result of these models is that the value an individual places on his own protection can be derived from information about the utility of his lifetime consumption. We turn now to examining the implication which this result has on the relationship between the willingnessto-pay and the human-capital approaches to the valuation of human life.

In the foregoing, it has been assumed that an individual is endowed with or will accumulate a certain wealth which, in the absence of bequests, takes the form of lifetime consumption. Alternatively, expected lifetime earnings could replace wealth, and thus lifetime consumption, as the relevant argument. It is important to keep this broad definition of lifetime consumption in mind when considering the following results.

Conley, who states at the outset that he is interested in determining the "value of human life with reference to an individual's wealth and utility function characteristics," concludes that "for income above some undetermined but presumably low level, the value of life is greater than discounted expected earnings ..." (p. 45). In principle, the Usher formulation is in agreement with this result.

This result can be illustrated by specifying a particular shape of the lifetime-consumption utility function. According to Conley, Figure 2 presents the general case in which a strictly concave utility function with $U^{L^{\prime}}>0$ will have three regions. In the first, $U^{L}<0$ and thus $\alpha<0$. In the second, $U^{L}>0$ but $\alpha>1$, therefore $V<C$. In the third, which may be called the general case, $0<\alpha<1$ and $V>C$; that is, for a value of expected lifetime consumption above some critical value where $\alpha=1$, a value which is presumably low, the value of human life exceeds expected lifetime consumption and, given no bequest motive, exceeds expected lifetime earnings.

Without any loss in generality the level of consumption at which a person can no longer survive can be set at zero so that the lifetime utility function passes through the origin. This is the approach taken by Rappaport in a report by Hirshleifer, et al. (1974), who assumes, 
FIGURE 2

The Relationship Between the Value of Life and

Lifetime Consumption as Derived by Conley

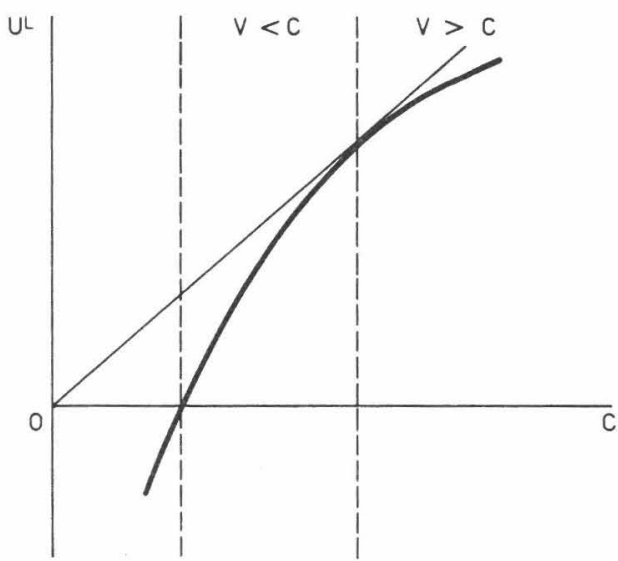

as a special case, that death corresponds to an income of $C=0$, or the person, when alive, considers death as the equivalent of an income of zero. He emphasizes the special case in recognition of the fact that most people are not indifferent between dying with zero income and dying with a positive income, since in most cases there is a bequest motive.

Given this assumption, Rappaport proceeds by analyzing the individual's response to a risky prospect yielding a $P$ chance of income, $C$, and a $Q=1-P$ chance of zero income. Since the utility of zero income is zero, the expected utility $E\left(U^{\boldsymbol{L}}\right)$ of this prospect can be expressed

$$
E\left(U^{L}\right)=P U(C)+Q U(0)=P U(C) .
$$

If the individual has a lifetime consumption of $C^{\prime}$, then the expected loss in utility from the hazardous prospect can be seen in Figure 3 as $\ell_{u}$, representing the difference between $U\left(C^{\prime}\right)$ and $E\left(U^{L}\right)$. In this figure $E\left(U^{L}\right)$ is simply $P$ times $U\left(C^{\prime}\right)$. The monetary equivalent (the amount of money the individual must be compensated to restore him to his original utility position of $U\left(C^{\prime}\right)$ ), noted $\ell_{c}$, is derived from the slope of the function and can be approximated for very small values of $Q$ as

$$
\ell_{c}=\ell_{u} /\left(d U^{L} / d C\right) .
$$

Since $\ell_{u}=Q U\left(C^{\prime}\right),(17)$ can be rewritten as

$$
\boldsymbol{\ell}_{c}=Q\left[\left(U\left(C^{\prime}\right) /\left(d U^{L} / d C\right)\right] .\right.
$$


FIGURE 3

Rappaport's Interpretation of the Value of Life

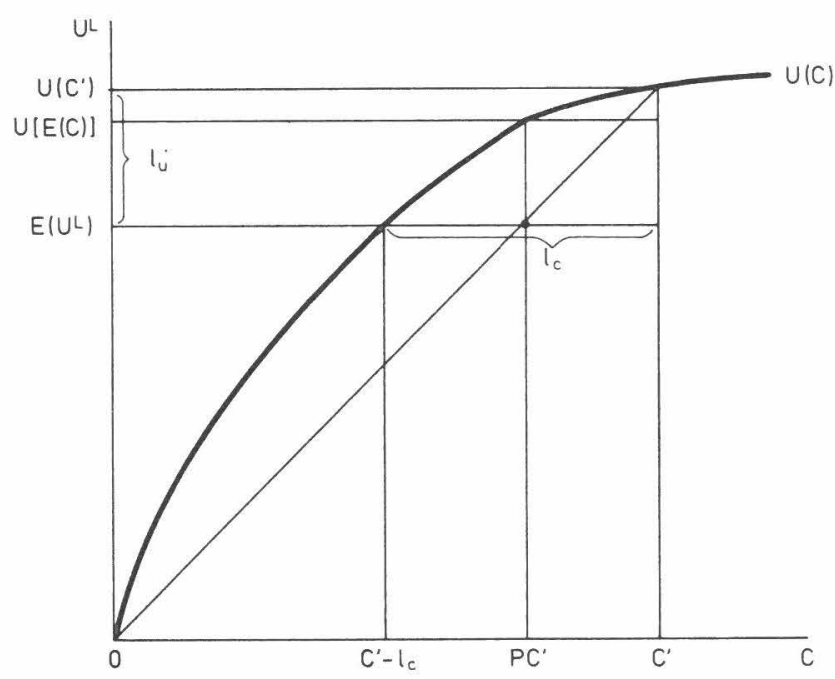

It follows from (18) that since $Q$ is the probability of dying, $\left(U^{L}\left(C^{\prime}\right)\right) /\left(d U^{L} / d C\right)$ must represent the value of human life. For very low $Q$ 's, or $p \approx 1$, this value is directly comparable to the value of life, $U(C) /\left(P\left(d U^{L} / d C\right)\right)$, which was derived by Usher and Conley.

The significance of this result is that given an assumption with respect to the form of an individual's consumption utility, the value of life can be calculated from data on personal consumption. As an illustration, Usher calculates this value from Canadian time-series data on net national product. Assuming that the utility of consumption takes the form,

$$
U_{t}(C)=\sum_{i=0}^{t-1} C_{i}^{b} /(1+r)^{i} .
$$

Usher is able to estimate values for $U_{t}(C)$ (in aggregate) by postulating a range of values for $b$ and $r$, where $1 / b$ represents a measure for the degree of diminishing marginal utility of consumption and $r$ is a subjective parameter representing the degree of utility time preference. By substituting this measure of $U_{t}(C)$ into his derived value of life (see Equation (9)) and with data on age-specific mortality rates, Usher is able to estimate the value of life (in the aggregate). For example, choosing $r=3$ per cent and $b=50$ per cent, he calculates the average value of life in 1961 to be $\$ 91,000$. The values ranged from $\$ 13,331,000(r=1 \%$, $b=5 \%)$ to $\$ 33,000(r=5 \%, b=100 \%)$.

We can conclude that the value of human life as formulated by Usher and Conley is formally similar to and empirically correlated with the human-capital measure. Indeed, if Usher's special form of consumption 
utility is hypothesized, then the value of life differs from life-time earnings only to the extent of diminishing marginal utility of lifetime consumption.

\section{AN ALTERNATIVE INTERPRETATION}

This rather surprising relationship between what an individual is willing to pay to reduce some probability of instantaneous death and his lifetime consumption follows directly from the assumed objective function of the two models. The only variable entering the individual's lifetime utility was assumed to be lifetime wealth, which in the absence of a bequest motive is equivalent to lifetime consumption.

If lifetime consumption is interpreted, according to Conley's definition, as total lifetime activities which incur positive monetary outlays, then it appears that this specification of the objective function is a somewhat narrow representation of a person's "joy of living." Indeed, it focuses only on the more materialistic side of life. Yet, the univariate specification of the objective function is central to the arguments of Usher and Conley, and for this reason it is important to give it careful consideration.

If a person perceives some level of consumption as being that level below which he cannot survive, it is reasonable in the absence of bequests to consider the utility of this level of consumption as equivalent to the utility of death. ${ }^{13}$ Again without any loss in generality the utility of this point can be arbitrarily set at zero. The lifetime utility function, $U^{L}$, and the lifetime consumption utility function, $U(C)$, have this one point in common. This seems to be the basis for the assumption that the functions are exactly equivalent, an assumption which is inherent in the above formulation of the risky prospect by Rappaport (see Equation 16).

However, the condition that $U^{L}(C=0)=U(C=0)=0$ is necessary, but not sufficient, for the result that $U^{L}=U(C)$. In fact, this result would not follow if $U^{L}$ were a discontinuous function of $C$ as illustrated in Figure 4. Here the assumption that a person views zero consumption, or zero wealth, as certain death represents simply a discontinuity in the curve, or a rather dramatic drop in one's lifetime utility. This interpretation, although certainly oversimplified, seems reasonable. Indeed, the original intent of Conley's formulation appears to capture the essence of this interpretation.

It can be recalled that Conley's objective function for period $t$ (see Equation (13)) is specified as a function of all lifetime activities which

13. It can be argued, however, that the assumption of zero consumption being equivalent to death holds only in the aggregate. Rappaport writes that zero consumption means that the individual "would be starving, thirsting, and exposed to the elements, i.e., he would be dead soon anyway" (p. 15). But here we are reminded that we are considering lifetime consumption as equivalent to lifetime earnings or wealth, and in reality most people do not view a total loss of their wealth, i.e., bankruptcy, as certain death 
he denotes $X^{t}$. Unfortunately, Conley then limits $X^{t}$ to consumption activities, which require a cash outlay, and production activities, which result in cash income. If we postulate a third category of neutral activities which require no monetary outlays or which result in no cash income, then we can respecify lifetime utility as

$$
U^{L}=\Sigma_{r} \lambda(t) u\left(Z^{t}, Q^{t}, C^{t}\right)
$$

where $Z^{t}, Q^{*}$, and $C^{t}$ denote neutral activities, production activities, and consumption activities, respectively. From this interpretation of the objective function, it follows that the value of human life derived from our simple model (see Equation (2)) cản be written

$$
\partial C / \partial P=-\left(U^{L}(Z, Q, C)\right) /\left(P U_{C}^{L}(Z, Q, C)\right),
$$

where $U_{C}^{\boldsymbol{L}}(\mathrm{Z}, Q, C)$ denotes the marginal lifetime utility of lifetime consumption.

We now want to ask what difference this derivation makes to the results of the Usher and Conley models. In which direction does it affect the relationship between the willingness-to-pay method and the humancapital method for the evaluation of a loss or savings of a human life?

To answer this question, we will assume for the sake of simplification that the utilities of neutral, production and consumption activities are separable and additive, or

$$
\begin{array}{ll}
U^{L}=U(C)+U(Z)+U(Q) & C>0 \\
U^{L}=0 & C=0 .
\end{array}
$$

Given this assumption, Conley's results (see Figure 2) are reinterpreted in Figure 4, which shows an additive transformation of the curve. This simple function, of course, is only an expositional device with no pretense of reality; yet, it does illustrate the point that as either $U(Z)$ or $U(Q)$ increases, $\alpha$ decreases. In other words, the higher an individual values his nonmaterial activities, the higher he values his life.

It remains to compare this derivation graphically with that by Rappaport. Figure 5 illustrates both his interpretation of the value of human life and our derivation, or reinterpretation, of this value. For purposes of comparison we continue to assume that zero consumption represents lifetime utility as specified by Usher and Conley; alternatively, $U^{L}$ represents the lifetime utility function which we have assumed here to be an additive function of neutral, production and consumption activities. $U^{L}$ and $U(C)$ are assumed parallel, the vertical distance between the two curves being $U(\mathrm{Z})$ plus $U(Q)$. $U^{\boldsymbol{L}}$ becomes discontinuous at $C=0$, at which point $U^{L}=0$.

The lower part of Figure 5 is recognizable as Rappaport's representa- 
ECONOMIC INQUIRY

FIGURE 4

A Possible Reinterpretation of Lifetime Utility

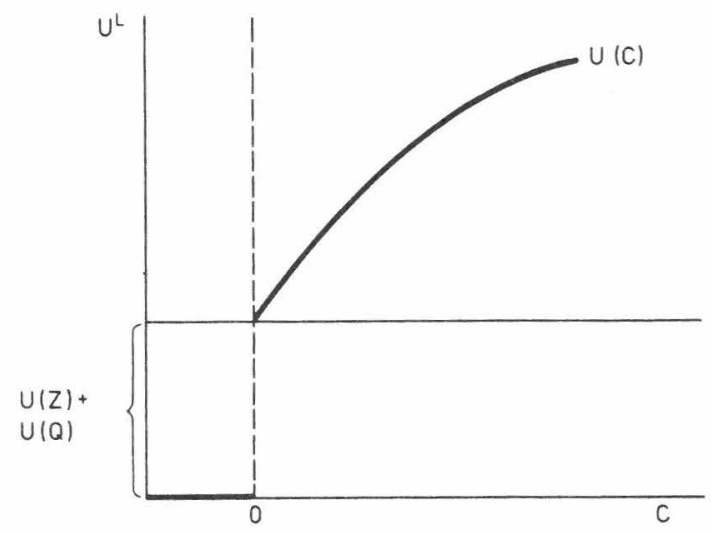

FIGURE 5

A Possible Reinterpretation of the Value of Life

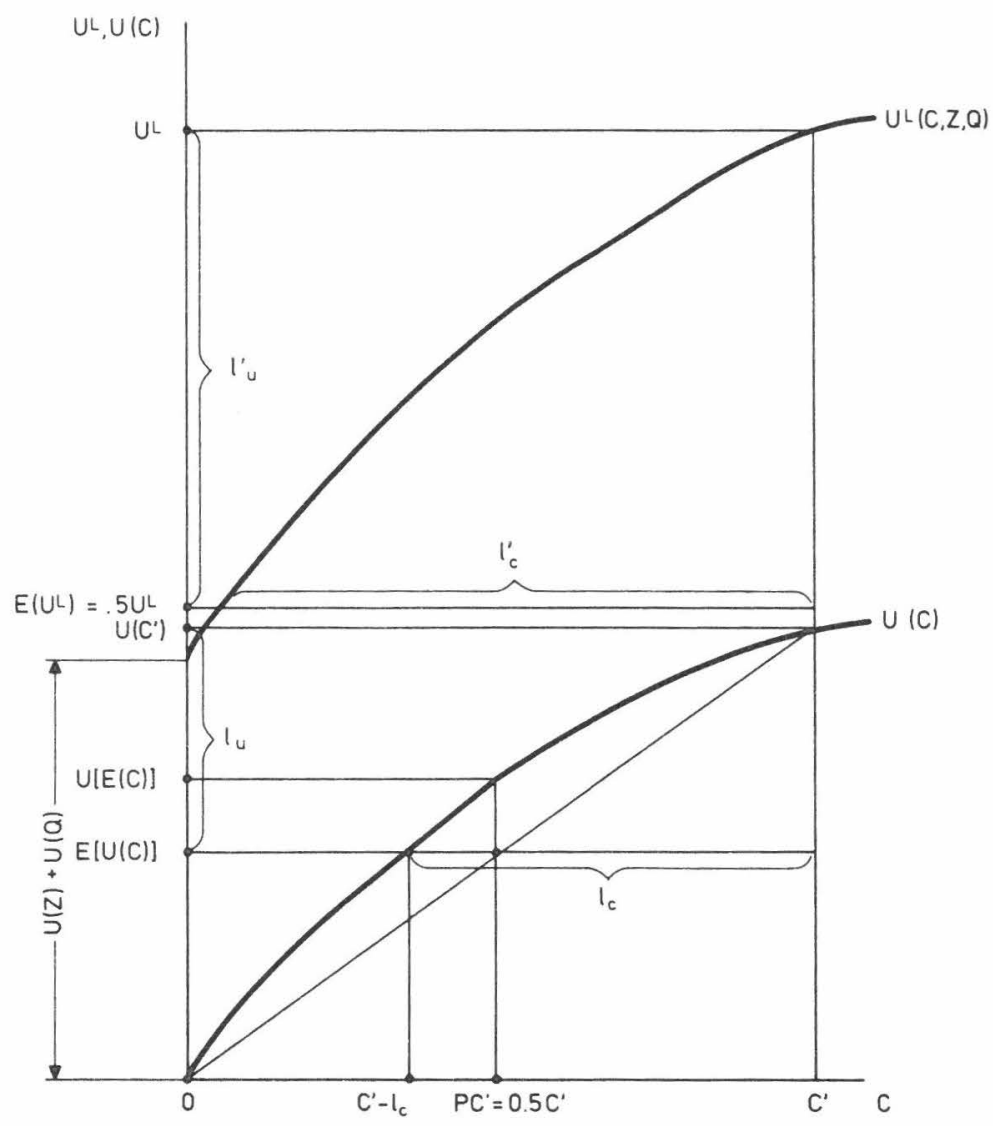


tion of Conley's derivation (see Figure 3). It can be easily seen from the upper part of Figure 5 that given our alternative interpretation of $U^{\boldsymbol{L}}$ this derivation underestimates the value of human life. For example, if $P=0.5$, then $\ell_{u}^{\prime}$ represents the loss in expected utility, in this case, $U^{L}-0.5 U^{L}$, and $\ell_{c}^{\prime}$ represents the necessary compensation to restore the individual to his original level of utility. Depending on the value of $U(Z)$ and $U(Q), \ell_{c}^{\prime}>\ell_{c}$, from which it follows that the Usher and Conley derivations underestimate the value of human life. From this specification of lifetime utility, we can conclude that lifetime earnings, which are represented here by $C$, can only be interpreted as a lower bound for this value.

This interpretation, however, depends upon the position of the $U^{L}$ function. Although it seems reasonable to assume that for most people the utility of living, as represented by $U^{L}(Z, Q, C)$ in Figure 5 , is somewhat greater than the utility of consumption, this need not be the case for everyone. To the contrary, this curve could lie beneath the present position of $U(C)$, in which case the person prefers death to some level of consumption above subsistence. This is the line of argument adopted by Cook (1976), who concludes that discounted earnings can only be considered an upper bound for the value of human life.

The position of the lifetime utility function is, of course, an empirical matter. The important point here is that there is no evidence to support the notion that it is continuous from the origin. We can conclude that the value of human life can in no way be correlated with expected lifetime consumption unless the investigator has, in addition, information on the utility of other arguments making up lifetime utility. ${ }^{14}$

\section{THE STATE-PREFERENCE APPROACH}

In light of the difficulties involved in disaggregating the lifetime utility function to any level which might be useful for empirical investigations, it seems reasonable to formulate lifetime utility simply as the utility of consumption conditional upon the states of the world "alive" and "dead." This is the approach of two models, the first by Jones-Lee and the second by Cook and Graham, each of which will be discussed in turn.

(i) Jones-Lee's Model ${ }^{15}$

Jones-Lee, who introduces the possibility of a bequest motive, assumes that an individual enters the period in question with a certain wealth and faces two contingencies: Either he survives the period, in which case

14. Hirshleifer, Bergstrom and Rappaport appear to recognize this limitation. Commenting on Usher's specification of lifetime utility, they write: "This function gives no weight to the fact of death except as it means loss of potential consumption income... No one has yet developed a utility function that captures the value of living per se" (p. 35).

15. Bergstrom's model (in Appendix 1 to the Hirshleifer, Bergstrom, Rappaport paper) is essentially the same as and contemporaneous with that of Jones-Lee. 
he and his dependents will enjoy his wealth, or he does not survive the period, in which case his dependents will enjoy their inherited wealth. Since total lifetime wealth is no longer allocated exclusively to lifetime consumption, the objective function is written as follows:

$$
E\left(U^{L}\right)=P_{0} U_{A}(W)+\left(1-P_{0}\right) U_{D}(W),
$$

where $U_{A}(W)$ is the utility of wealth conditional on the state of the world "alive" and $U_{\boldsymbol{D}}(W)$ is the utility of wealth conditional on the state of the world "dead." The maximization of $E\left(U^{L}\right)$ is straightforward and results in the condition which has been defined here as the value of human life, or

$$
\partial W / \partial P_{0}=-\left[U_{A}(W)-U_{D}(W)\right] /\left[P_{0} U_{A}{ }^{\prime}(W)+\left(1-P_{0}\right) U_{D}{ }^{\prime}(W)\right],
$$

where $U_{A}{ }^{\prime}(W)$ and $U_{D}{ }^{\prime}(W)$ are the marginal lifetime utility and the marginal lifetime bequest utility with respect to wealth, respectively. As might be anticipated, a person's desire to leave a certain amount of his wealth to his dependents decreases his willingness to pay for his own safety. In the absence of a bequest motive, the above expression is identical to the previously derived value of life (see Equation (2)) with the important exception that here the term $U_{A}(W)$, representing the utility of wealth conditional upon the state of the world "alive," substitutes for the term $U(C)$. For purposes of providing a basis for empirical investigations, this distinction is crucial.

(ii) The Cook and Graham Model

In many respects, Cook and Graham (1975) present a unique analysis of the problem of establishing the value for individual risk reduction or, in their words, the value of collective protection. Following Jones-Lee, they also adopt the state-preference framework, where there are two states of the world, "alive" and "dead," and where the utility of the state "dead" represents a bequest utility. Their approach is especially interesting in that they view human life as one commodity within a general class of irreplaceable commodities. An irreplaceable commodity can be distinguished from a replaceable commodity by determining whether in the owner's view there are equivalent commodities available on the market. A person's life can be considered irreplaceable, as can the family dog, an ancestor's portrait, and so forth.

Cook and Graham suggest that the value of protection (decreasing the probability of loss) of a commodity is the value of this protection when fair transfers of wealth or fair insurance are available. This value is defined as the pure protection benefit of a public investment. An important conclusion of their analysis is that, contrary to the case of the replaceable commodity, the pure protection benefit of an irreplaceable commodity is greater than the amount of fair insurance the indi- 
vidual would choose to purchase. In assessing the benefit of an increase in public protection, the correct value of a commodity is bracketed by the amount of money the owner would pay to avoid its loss and the amount of money required to fully compensate him for its loss, or in Hick's (1959) terminology, it is bracketed by the equivalent variation and the compensating variation.

Their analysis proceeds by specifying two states of the world, A and B, with the following properties:

$$
U_{A}(W)=U(W, 1),
$$

and

$$
U_{B}(W)=U(W, 0) .
$$

Here, $W$ represents a composite commodity (wealth) including all goods other than the commodity in question, 1 represents the state in which the commodity is kept and 0 the state in which it is lost. It is assumed that ${ }^{16}$

$$
U_{i}^{\prime \prime}(W)<0<U_{i}^{\prime}(W) \text { for } i=A, B .
$$

From the above equations, Cook and Graham suggest two possible measures for the value of the good. One measure is the minimum compensation (selling price) that would induce the individual to accept a certainty of state 0 in exchange for a certainty of state 1 . This compensation $C(W)$ is defined by

$$
U_{A}(W+C(W))=U_{B}(W),
$$

provided that such a $C(W)$ exists and $C(W)=\infty$, otherwise. Alternatively, the value of a good can be expressed as the maximum amount the individual would be willing to pay to exchange a certainty of state 0 for a certainty of state 1 . The ransom $R(W)$ is defined by

$$
U_{B}(W)=U_{A}(W-R(W)),
$$

provided that such an $R(W)$ exists and $R(W)=0$, otherwise.

The ransom, in turn, is closely related to the amount of insurance an individual will purchase at fair odds. Assuming fair transfers of wealth between states A and B, the individual's expected wealth can be defined

$$
W \equiv P \bar{W}_{A}+(1-P) \bar{W}_{B}=P W_{A}+(1-P) W_{B},
$$

16. Note that this assumption, which is also found in the Jones-Lee analysis, contradicts the function presented in Section 4 (see Figure 4); however, here it is not assumed that $U_{A}(W=0)=$ $U_{B}(W)$. 
where $(1-P)$ is the probability of loss, $\bar{W}_{i}(i=A, B)$ is endowed wealth in state $i$, and $W_{i}(i=A, B)$ is the financial claim contingent upon state $i$ to be purchased. Expected utility

$$
E(U)=P U_{A}\left(W_{A}\right)+(1-P) U_{B}\left(W_{B}\right)
$$

is maximized subject to (27). The solutions $W_{A}^{*}$ and $W_{B}{ }^{*}$ have the following property:

$$
U_{A}^{\prime}\left(W_{A}^{*}\right)=U_{B}^{\prime}\left(W_{B}^{*}\right)
$$

where

$$
W_{B}^{*}=\left(W-P W_{A}^{*}\right) /(1-P) \text {. }
$$

The authors show further that an individual will insure himself completely against the loss of a replaceable commodity, that is, he is indifferent as to what state occurs. In this case, the ransom, $R(W)$, will be equal to $W_{B}{ }^{*}-W_{A}{ }^{*}$. Alternatively, the individual will not insure himself completely against the loss of an irreplaceable commodity; he will prefer state $\mathrm{A}$ to state $\mathrm{B}$, and $R\left(W_{A}^{*}\right)>W_{B}{ }^{*}-W_{A}{ }^{*}$.

With this information, it is possible to specify the pure protection benefit for an increase in an individual's probability of survival, where the pure protection benefit is defined as the expected payment made by the individual (given fair insurance), which, when coupled with an increase in his survival chances, leaves his expected utility unchanged. For small changes in survival probability, this definition is represented by the slope of the indifference function (see Figure 1) where the possibility of fair insurance is taken into account. Therefore, what Cook and Graham more appropriately label as the pure protection benefit is equivalent to what has been defined here as the value of human life when given the opportunity to purchase fair insurance.

The slope of this indifference function can be specified in the usual manner. Letting state A represent the state "life" and state D (substituting D for B), the state "death," Equations (27), (28) and (29) can be rewritten

$$
\begin{aligned}
& W(P) \equiv P W_{A}^{*}(P)+(1-P) W_{D}^{*}(P), \\
& E U=P U_{A}\left(W_{A}^{*}(P)\right)+(1-P) U_{D}\left(W_{D}^{*}(P)\right), \\
& U_{A}^{\prime}\left(W_{A}^{*}(P)\right)=U_{D}^{\prime}\left(W_{D}^{*}(P)\right) .
\end{aligned}
$$

Differentiating the above equations with respect to $P$ and simplifying, Cook and Graham get 


$$
\partial W / \partial P=-W_{D}^{*}-W_{A}^{*}+\left(U_{A}\left(W_{A}^{*}\right)-U_{D}\left(W_{D}^{*}\right)\right) / U_{D}^{\prime}\left(W_{D}^{*}\right) .
$$

Substituting (30) into (31) yields

$$
\partial W / \partial P=-\left(W_{D}^{*}-W\right) / P+\left(U_{A}\left(W_{A}^{*}\right)-U_{D}\left(W_{D}^{*}\right)\right) /\left(U_{D}^{i}\left(W_{D}^{*}\right)\right),
$$

which bears a close resemblance to the value of human life derived in the last section (see Equation (20)). As expected, this value or slope is directly related to the utility of living $U_{A}\left(W_{A}{ }^{*}\right)$; however in this model, contrary to Usher's and Conley's, $U_{A}\left(W_{A}^{*}\right)$ represents the utility of life with wealth $W_{A}{ }^{*}$ and not simply the utility of wealth. Again, for the purpose of providing a theoretical basis for quantifying willingness to pay for mortality risk reduction, this distinction is critical.

Finally, it is possible to establish a relationship between the pure protection benefit of the commodity and the individual's purchase of fair insurance. Cook and Graham have shown above that for the case of the replaceable commodity the opportunity to purchase insurance at fair odds implies that $U_{A}=U_{B}$; thus for a replaceable commodity it follows from (31) that $-\left(W_{B}^{*}-W_{A}^{*}\right)$ represents the pure protection benefit, which is identical to the ransom value $R\left(W_{A}{ }^{*}\right)$. The price appropriate for calculating the value of reducing the probability of losing a replaceable commodity can thus be inferred directly from knowledge of the amount of insurance that the individual would purchase at fair odds.

Alternatively, in the case of an irreplaceable commodity, where $U_{A}>U_{B}$, the appropriate value cannot be inferred from insurance protection purchases. In fact, the authors show that for an irreplaceable commodity the pure protection benefit implies a value for its loss which is bracketed by the amount the owner is willing to pay to avoid its loss $R(W)$ and the amount of money required to fully compensate him for its loss $C(W)$. Given the assumptions of this analysis, the implied value of a person's life would be bracketed by the amount of his budget and the "infinite" amount required to fully compensate him for accepting certain, immediate death. Insofar as his budget constraint is interpreted as being the present value of his expected earnings, the human-capital approach to life valuation reflects only a lower bound to the value of human life.

\section{CONCLUDING REMARKS}

The conclusion of this review is that there are no theoretical grounds for establishing an empirically useful relationship between the value, in the form of Hicksian compensating variations in wealth, of current period changes in a person's risk of death and his lifetime earnings. The significance of this conclusion to the cost-benefit analyst is that there 
is no testable relationship between the willingness-to-pay and the humancapital approaches to placing a value on the loss of a human life.

The modelling work in this area has resulted in important insights with respect to a person's response to changes in his survival chances and his lifetime earnings, his possibilities for bequeathing his wealth and his insurance options; however, it has not provided the analyst with a theoretical basis for effectively quantifying personal demand for mortality risk reduction. Usher, who was the first to introduce uncertain mortality into a model of consumer choice, assumed that the consumer has both knowledge of and control over his survival probability. Conley took a slightly different approach by introducing behavioral variables. Both models generate a number of interesting results regarding a person's tradeoff of lifetime consumption for increased survival chances, including the finding with which we have been most concerned - namely, that this tradeoff is a quantifiable function of lifetime consumption. However, we have shown in this review that this important result follows from the assumption that lifetime utility is equivalent to the utility of lifetime consumption.

If we assume instead that the utility of lifetime consumption serves only as a lower bound to a person's utility of living, then we can conclude only that a person's lifetime earnings serve as a lower bound to his willingness to pay for a decreased chance of premature death. This is a conclusion of the Jones-Lee and of the Cook and Graham models, each of which adopts the less restrictive state-preference formulation of lifetime utility. According to the state-preference approach lifetime utility is a function of wealth conditional upon the states "alive" and "dead." A utility associated with the state of being dead requires the introduction of a bequest motive into their analyses. In addition, Cook and Graham introduce a unique definition of the value of life, which they refer to as the value of collective protection, requiring the existence of fair insurance. They conclude, however, that knowledge of the amount of insurance an individual purchases to insure himself against the loss of an irreplaceable commodity, such as his life, cannot lead to the calculation of the price appropriate for valuing the reduction of the probability of its loss.

Unfortunately, it appears that there are limited possibilities to provide policy makers with meaningful data on personal willingness to pay for reduced mortality risk, regardless of whether these data are obtained from market behavior, from questionnaires or indirectly from personal lifetime earnings. Mishan is correct in reminding us that it is better to proceed with "rough estimates of the precise concept than precise estimates of economically irrelevant concepts," 17 but it is important for 
the analyst to recognize that life value estimates are rough. For this reason, cost-benefit calculations, especially in the area of public health and safety, should continue to be regarded as only an aid to the public decision process.

\section{REFERENCES}

Acton, J. P., "Evaluating Public Programs to Save Lives: The Case of Heart Attacks," Santa Monica, California: Rand Corp. Report R-950-RC, January 1973.

Bailey, M. J., "Comment on T. C. Schelling's Paper 'The Life You Save May Be Your Own,'” in Problems in Public Expenditure, edited by Samuel B. Chase, Washington, D.C.: Brookings Institute, 1968.

, "Benefits of Safety," Draft Report, University of Maryland, December 1975.

Bergstrom, T. C., "Preference and Choice in Matters of Life and Death," Appendix 1 in Applying Cost-Benefit Concepts to Projects Which Alter Human Mortality, by J. Hirshleifer, et al., University of California, 1974.

Conley, B. C., "The Value of Human Life in the Demand for Safety," American Economic Review, $66,45-55,1976$.

Cook, P. J., “The Earning's Approach to Life Valuation: A Reply to Conley," Draft Report, Duke University, Durham, North Carolina, 1976.

, and Graham, D. A., "The Demand for Insurance and Protection: The Case of the Irreplaceable Commodity," Draft Report, Duke University, North Carolina, 1975.

Dublin, L. I., and Lotka, A. J., The Money Value of a Man, New York: Ronald Press, 1940.

Fisher, I., "Report on National Vitality," Bulletin 30 of the Committee of One Hundred on National Health, Washington, D.C.: Government Printing Office, 1909.

Fried, C., "The Value of Human Life," Harvard Law Review, 82, 1415-37, May 1969.

Fromm, G., "Civil Aviation Expenditures," in Measuring Benefits of Government Investment, edited by R. Dorfman, Washington, D.C.: Brookings Institute, 1965.

" "Comment on T. C. Schelling's Paper 'The Life You Save May Be Your Own,", in Problems in Public Expenditure, edited by Samuel B. Chase, Washington, D.C.: Brookings Institute, 1968.

Hicks, J. R., A Revision of Demand Theory, Oxford: Oxford University Press, 1959.

Hirshleifer, J., Bergstrom, T., and Rappaport, E., Applying Cost-Benefit Concepts to Projects Which Alter Human Mortality, Los Angeles: University of California, 1974.

Jones-Lee, M., "The Value of Changes in the Probability of Death or Injury," Journal of Political Economy, 99, 835-49, July-August 1974.

Lave, L., and Seskin, E. P., “Air Pollution and Human Health,” Science, 169, 723-33, August 1970.

Linnerooth, J., The Evaluation of Life-Saving: A Survey, Research Report RR-75-21, International Institute for Applied Systems Analysis, Laxenburg, Austria, 1975. "Methods for Evaluating Mortality Risk," Futures, 8, No. 4, August 1976.

"The Evaluation of Public Programs Affecting Population Mortality," unpublished Ph.D. dissertation, University of Maryland, College Park, 1977.

Luce, R. D., and Raiffa, H., Games and Decisions, New York: Wiley, 1957.

Mishan, E. J., "Evaluation of Life and Limb: A Theoretical Approach, Journal of Political Economy, 79, 687-705, July/August 1971.

Morlat, G., "Un Modele Pour Certaines Decisions Medicales," Cahiers du Seminar d'Econometrie, Centre National de la Recherche Scientifique, 1970.

Neumann, J., von, and Morgenstern, O., Theory of Games and Economic Behavior, 2nd ed., Princeton, New Jersey: Princeton University, 1974. 
Otway, H. J., Maderthaner, R., and Guttmann, G., Avoidance Response to the Risk Environment: A Cross-Cultural Comparison, Research Report RR-75-14, International Institute for Applied Systems Analysis, Laxenburg, Austria, 1975.

, Lohrding, R. K., and Battat, M. E., “A Risk Estimate for an Urban Sited Reactor," Nuclear Technology, 12, 173-87, October 1971.

Raiffa, H., Schwartz, W., and Weinstein, "On Evaluating Health Effects of Societal Programs," Draft Report, Panel on Evaluative and Integrating Procedures, Boston, Mass., 1976.

Rappaport, E., "Economic Analysis of Life-and-Death Decision-Making," Appendix 2 in Applying Cost-Benefit Concepts to Projects Which Alter Human Mortality, by J. Hirshleifer, et al., University of California, 1974.

Reynolds, D. J, "The Cost of Road Accidents," Journal of the Royal Statistical Society, 119, 398-708, 1956.

Roesch, B., "De Quelques Prolongements et Ramifications en Divers Domaines," Revue Francaise Recherche Operationelle, 19, 125-38, 1961.

Savage, L. J., The Foundations of Statistics, New York: Wiley, 1954.

Schelling, T. C., “The Life You Save May Be Your Own," in Problems in Public Expenditure, edited by Samuel B. Chase, Washington, D.C.: Brookings Institute, 1968.

Smith, R., "Compensating Wage Differentials and Hazardous Work," Technical Analysis Paper No. 5, Office of Policy Evaluation and Research, Department of Labor, August 1973.

Starr, C., "Societal Benefit versus Technological Risk," Science, 165, 1232-48, September 1969.

Thaler, R., and Rosen, S., "Estimating the Value of Saving a Life: Evidence from the Labor Market," preliminary report prepared for the Conference on Research in Income and Wealth, New York: National Bureau of Economic Research, 1973.

Thedie, J., and Abraham, C., "The Economic Aspects of Road Accidents," Traffic Engineering and Control, 2, 10, February 1961 .

Usher, D., "An Imputation to the Measure of Economic Growth for Changes in Life Expectancy," Conference on Research in Income and Wealth, New York: National Bureau of Economic Research, 1971.

Weisbrod, B. A., “Burial Costs and Premature Death," Journal of Political Economy, 73, 504-8, June 1965 .

Woods, E. A., and Metzger, C. B., America's Human Wealth: The Money Value of a Human Life, New York, Kelly, 1927.

Zeckhauser, R., "Procedures for Valuing Lives," Harvard University School of Government Public Policy Program Discussion Paper 29D, rev. ed. Cambridge, Mass., 1975.

U.S. Department of Transportation, National Highway Safety Administration, "Societal Costs of Motor Vehicle Accidents," preliminary report, Washington, D.C., 1972.

White House Office of Science and Technology, Cumulative Regulatory Effects on the Costs of Automotive Transportation, Washington, D.C.: Government Printing Office, 1972. 
